\title{
WestVirginiaUniversity
} THE RESEARCH REPOSITORY @ WVU

Graduate Theses, Dissertations, and Problem Reports

2020

\section{Making a Dent}

\author{
Emily Morwood \\ West Virginia University, em0076@mix.wvu.edu
}

Follow this and additional works at: https://researchrepository.wvu.edu/etd

Part of the Appalachian Studies Commons, Journalism Studies Commons, and the Social Influence and Political Communication Commons

\section{Recommended Citation}

Morwood, Emily, "Making a Dent" (2020). Graduate Theses, Dissertations, and Problem Reports. 7796. https://researchrepository.wvu.edu/etd/7796

This Problem/Project Report is protected by copyright and/or related rights. It has been brought to you by the The Research Repository @WVU with permission from the rights-holder(s). You are free to use this Problem/Project Report in any way that is permitted by the copyright and related rights legislation that applies to your use. For other uses you must obtain permission from the rights-holder(s) directly, unless additional rights are indicated by a Creative Commons license in the record and/ or on the work itself. This Problem/Project Report has been accepted for inclusion in WVU Graduate Theses, Dissertations, and Problem Reports collection by an authorized administrator of The Research Repository @ WVU. For more information, please contact researchrepository@mail.wvu.edu. 


\section{WestVirginiaUniversity}

THE RESEARCH REPOSITORY @ WVU

Graduate Theses, Dissertations, and Problem Reports

2020

Making a Dent

Emily Morwood

Follow this and additional works at: https://researchrepository.wvu.edu/etd

Part of the Appalachian Studies Commons, Journalism Studies Commons, and the Social Influence and Political Communication Commons 
Making a Dent

Emily Morwood

Professional Project submitted to the Reed College of Media at West Virginia University in partial fulfillment of the requirements for the degree of

Journalism in the Reed College of Media

\author{
Clifton David Smith, M.A., Chair \\ Mary Kay McFarland, M.A. \\ Bob Britten, Ph.D. \\ Stevie M. Munz, Ph.D \\ Reed College of Media
}

Morgantown, West Virginia
2020

Keywords: othering, documentary film, Standpoint Theory, opioids, opioid epidemic, United States, U.S., insider, outsider, Logan West Virginia, Southern West Virginia

Copyright 2020 Emily Morwood 


\section{ABSTRACT}

Making a Dent

\section{Emily Morwood}

West Virginia's opioid-related death rates have surpassed any other state since 2014, with projections that it will continue to do so. With the epidemic, largely negative and stereotypical accusations have come, which have led to "othering," or the concept of making groups 'other' due to their differences. This documentary project's purpose is to address those that have been put in those othered groups through the concept of Standpoint Theory, which argues that insiders to a situation should tell their stories, rather than outsiders. The project aimed to allow the participants to tell their perspectives on the epidemic as insiders in order to provide a clearer understanding of what is occurring in Logan, West Virginia. 
Table of Contents

Title.

Abstract

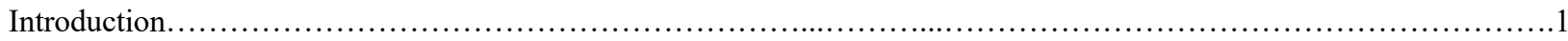

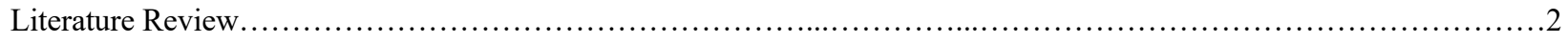

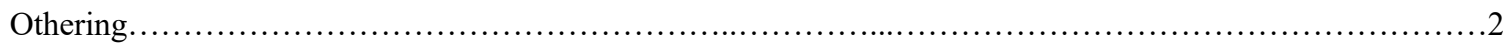

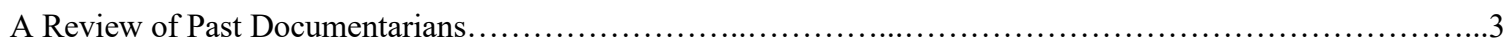

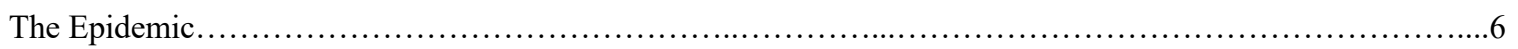

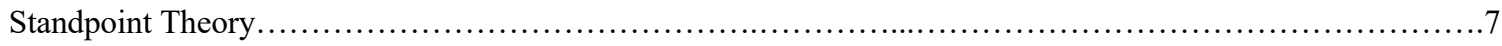

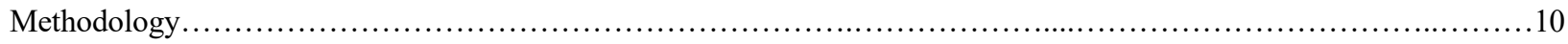

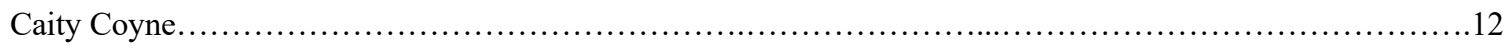

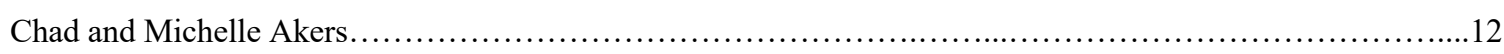

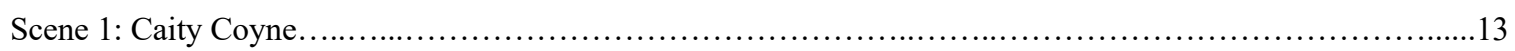

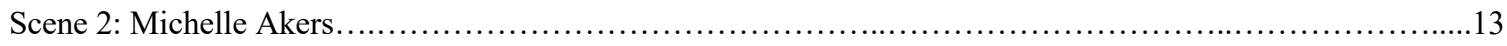

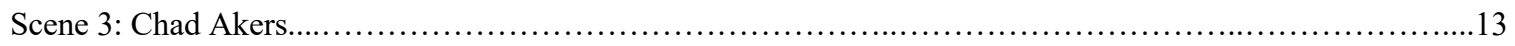

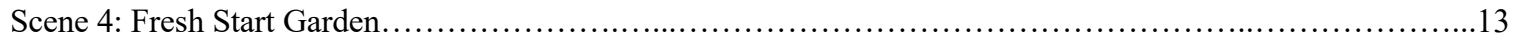

Scene 5: Chad and Michelle - Bruising the monster................................................. 13

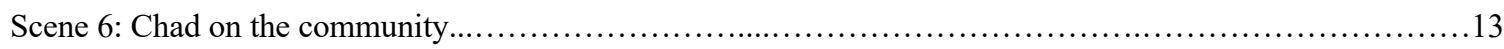

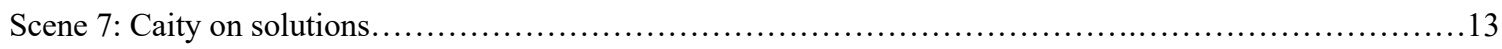

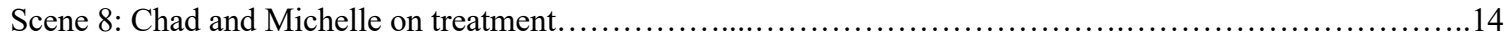

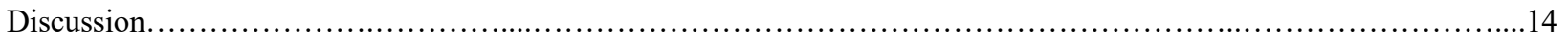

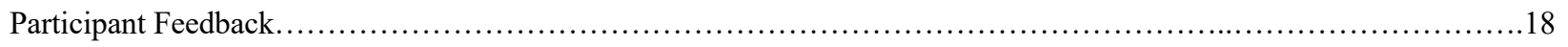

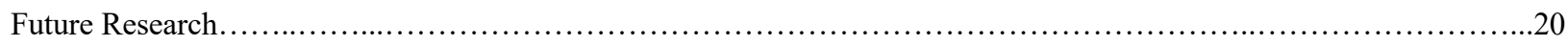

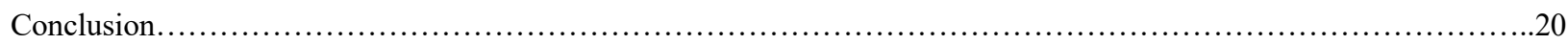

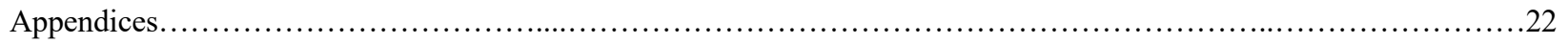

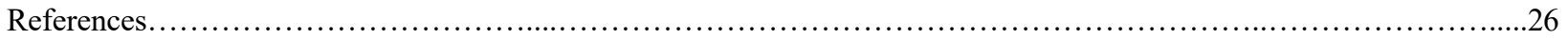




\section{Making a Dent}

\section{Introduction}

In 2014, West Virginia led with the most opioid-related overdose deaths in the United States at 122 deaths. Within just three years, those numbers increased over 500 percent to 833 deaths (NIDA, 2019). This increase has led to much discussion about why West Virginia is so affected. The conclusions that the epidemic has brought is furthering something West Virginia has been a victim of for decades: othering (Hess et al., 2018; Scott, 2009). Othering is the process that marks a group or individual that is thought to be different from another (Canales, 2000; Hess et al., 2018; Scott, 2009). As Conquergood (2003) argues, "When we have true respect for the Difference of other cultures, then we grant them the potential for challenging our own culture" (p. 9). Challenging one's own culture gives an opportunity to recognize the "other" within one's identity, making it possible to find similarities within cultures as well, which makes the issue even more complicated in the case of West Virginia. The othering the state is experiencing, both from West Virginians themselves and those outside the state, is extremely complicated. It is also a slippery slope that can lead to stereotyping, false information, and a lack of solutions when looking at West Virginia's opioid epidemic (Scott, 2009). Further, the othering is emphasized through film, photo, and literature, and highlights West Virginians as low-income, uneducated, poverty-stricken, and unsanitary, and many label its residents with the derogatory term "hillbilly" (Scott, 2009; Rubin and York, 2019; Stewart, 1996). These depictions only deflect from finding real solutions, as the people of West Virginia are seen only as their stereotypes.

Othering makes for an insider/outsider standpoint that further agitates the situation: that is, the relationship of those unfamiliar or misinformed with the circumstances, and those in West Virginia affected most by the epidemic. It is West Virginians who are directly affected by large pharmaceutical companies who are shipping millions of opioids to many parts of the state in an unreasonably short amount of time (Eyre, 2018). It is the West Virginian, the one who has directly experienced the state's opioid epidemic, who understands their state's circumstances best. Many West Virginians have become insiders to this epidemic, and they are the ones given authority to speak on this matter. An outsider, in this 
case one who has not experienced the direct or secondary effects of the West Virginia opioid epidemic, might know what media have shown, but they are not living it as the insiders are, which makes the situation extremely complex and muddled. However, it is important to recognize that determining who qualifies as an insider or outsider is impossible. Some that would consider themselves insiders in one way may be looked at outsiders from a different regard. That said, the project will be looking at these definitions of insider and outsider with the idea in mind that both insider/outsider perspectives are extremely subjective and personal.

The proposed project aims to start a dialogue concerning the effects of the opioid epidemic. It will accomplish this by focusing on the effects of othering by media and outsiders when it comes to those directly trying to find solutions to the epidemic, and it will be through the lens of Standpoint theory. The project will be a short documentary film that will illuminate the disparate perspectives and experiences of those affected, including a funeral director, a clinical psychologist at a day program, and a journalist.

\section{Literature Review}

Othering

Canales (2000) argues that the differences in societies and cultures shift through time, distance, and perspectives. However, Canales (2000) cites the definition of the concept, saying othering is “"that process which serves to mark and name those thought to be different from oneself'" (qtd. in Canales, 2000, p. 18). Canales (2000) discusses that when the othering is exclusionary that it becomes dangerous (Canales, 2000). Stewart (1996) situates the explanation of the harmful effects of othering, this time in regard to West Virginians specifically who live in the hollers or those who are in the lower class. The dominant group, with privilege in leaving a legacy for the world, does not see what those othered see. The othered group are seen as the dirty and ignorant, so they are put further into their othered spaces (Stewart, 1996). The othering goes so far that it implements its own insider and outsider perspectives. It separates the groups into the dominant and the other, leaving one weaker than the other. Instead of both groups being able to tell their story, they are left with the stronger, more dominant one to decide narratives for both. It is then, when othering is based around solidifying harsh stereotypes about the othered group, 
limiting a group or person to nothing more than that stereotype, that further misinformation and limitations follow--and when this occurs on a broad scale, often through media, it only furthers that exclusionary process.

Scott (2009) discusses one example of media harming others. While the goal of the message was to call attention to the injustices Appalachia is experiencing, she argued that it still hammered in stereotypes and assumptions about the region (Scott, 2009). Scott (2009) emphasizes some of these stereotypes that are emphasized--that Appalachians are dirty, inbred, poverty-stricken, showing a "monochromatic misery, passivity and squalor" (p. 11). However, the othering does not stop at the end of the message. Scott (2009) further argues, "[The media] may unwittingly recreate the experience of othering on the part of the consumers of these images. Photographs can educate and motivate the viewer, but at the same time confirm ideologies of superiority, inferiority, and colonizing relationships (Scott, 2009, p. 8). Stewart (1996) further discusses the history of the way West Virginians and Appalachians have been seen through popular culture. Although West Virginia was once seen as "tough pioneers," they were always othered (Stewart, 1996, p. 118). However, the area has since become "a distinct area marred by the culture of poverty" (Stewart, 1996, p. 119). The contradictions that were pushed on West Virginians have only furthered the dominant from the othered culture. Stewart's (1996) and Scott's (2009) work shows that othering is dangerous because it spreads so easily and it is so engrained already. If one person can convince another that a group or individual has derogatory differences, those differences can spread, making the group or individual separate indefinitely.

\section{A Review of Past Documentarians}

One documentarian, for instance, was raised in middle-class Appalachia and has since gone back to poverty-stricken areas, to photograph and document the lifestyles in the area. Despite being a part of Appalachia, Shelby Lee Adams' (2002) work is extremely controversial. Huettner (2011) asks, "At what point does artistic license to portray a region become a mythologizing or branding effect that exploits the poverty of others for profit?" (n.p.). Although Adams (2002) has extraordinary photos, he surpasses the act of simply documenting the subjects; instead, his work comes off, as Huettner (2011) states, as close to 
“poverty porn." Harvey (2003) furthers this argument, saying, "Result makes these 'hollar [sic] dwellers' look grotesque and pathetic” (n.p.). Many see Adams' (2002) work as dignifying poor West Virginians, showing their lifestyles in an art form that makes their voices heard. Huettner (2011) mentioned that Adams' sees himself as an insider who understands and befriends Appalachia, but Huettner also suggests that Adams' work is coming from the perspective of an outsider. Adams grew up in a middle-class family in Kentucky and only saw extreme poverty when he would go on business trips with his father (Huettner, 2011). Experiencing a middle-class family in Kentucky makes Adams an insider in some regards, such as being from Appalachia, but it does not to the extent that he was a part of the culture he was photographing. This makes for a complicated argument, as arguably Adams' (2002) depictions of people from his home state of Kentucky are othering in a very public and exploitative way. The documentarian neglects to show the realities outside of what he has staged. He is simply furthering the stereotypes of Appalachia, under the credence of being a part of the culture.

According to Hess et al. (2018), "The negative stereotypes of people from Appalachia have been constructed predominantly by those not from the region...an important distinction is made regarding the positioning of those who have the 'means'-be it through colonization, academic knowledge, or cultural hegemony — to create a dominate $[$ sic $]$ narrative" (p. 11). In other words, those with the power are in control of the narrative, whether that be insiders' othering or outsiders. Scott's (2009) critical analysis of Light's (2006) photographic documentary book, Coal Hollow, depicts many of the same themes. Scott (2009) claims that the depiction bases its perspective on what the common conclusions of Appalachia are: poor, dirty, and unkempt. Further, Scott (2009) states, "This is the logic of meritocracy, which blames the victims of social, economic, or environmental devastation for their own problems, and reassures the rest of 'us' that these disasters are the exception, not the norm" (p. 9). Light's (2006) perspective of "us vs. them" is only detrimental to the reality of Appalachia, the stereotypes that ensue, and to the perspectives of those that look no further than their depiction.

On the other hand, documentarians such as Elaine McMillion Sheldon have created a perspective of what individual West Virginians are experiencing, specifically those in treatment programs recovering 
from opioid addiction. She does this by allowing the people she is documenting control the narrative, as she stands by with a camera to show it. For example, the LA Times review of Sheldon's (2018) Recovery Boys, states, "In a state fighting the scourge of opiate addiction, Sheldon presents Jacob's Ladder as a bright light, building a recovery community on the values of love, compassion and understanding" (Walsh, 2018, n.p.). Sheldon's work in Heroin(e) (2017) and Recovery Boys (2018) focuses on the people of the epidemic, rather than looking at the external factors of their situation. By allowing people to tell their stories instead of giving them a staged story, a much more engaged and empathetic light is shown.

In a Huffington Post interview, Sheldon (2017) discussed documentaries that are agenda based rather than human based. She said, "If you go into making a documentary and you have all the answers and you're just asking a series of questions to get those answers, I think you should work in advertising. If you're not willing to be challenged and hold two conflicting viewpoints at the same time and be OK with that, because that's what humans are, then I think the documentary is lacking in substance" (Sheldon, 2017, n.p.). Kranitz (2019) is another documentarian that holds to a similar argument. Being a Kentucky native, she has been photographing Appalachia for over a decade. However, she said she became disenchanted with documentary work, as it did not seem as honest as before (Angelos, 2019). She realized the poverty and the way the media latches on to that, so she began a new project. Rather than focusing on the stereotypes and misrepresentation of Appalachia, she fully immersed herself into the culture (Angelos, 2019). She did not just go through to ask a series of questions, but she instead forced herself to build long-term relationships to show accurate depictions, which makes her photography seem extremely respectful, honest and accurate.

Although there are documentarians, journalists, and other media coverage on the epidemic, there is very little research that covers this othering in regard to the opioid epidemic, which is why it is so critical for the proposed study to highlight what is occurring throughout West Virginia. Appalachia, and specifically the state, have been stereotyped and othered for decades due to sociocultural, political, and other factors, but to look at the detrimental effects that the opioid epidemic is posing is necessary. As Phillips and Earle (2010) argue, if researchers and outsiders alike are looking to provide any opportunity 
to disrupt the othering, accounts might be produced to be more than a report of something one does not know. It is up to those with the power and influence to change the stereotypes that Appalachia is experiencing, especially when it comes to the opioid epidemic.

The Epidemic

Opioids, a class of drugs that include heroin and fentanyl, are also pain relievers available by prescription, such as oxycodone, hydrocodone, codeine and morphine, among others (NIDA, 2019). The spread of addiction to these opioids has caused an epidemic that is responsible for more deaths throughout the U.S. than the number of deaths by suicide and car crashes combined (Manchikanti et al., 2012). In 2017 , state providers wrote an average of 81.3 opioid prescriptions for every 100 persons, which is extremely high compared to the national rate of 58.7 (NIDA, 2019). West Virginia also is first in neonatal opioid withdrawal symptoms, first in fatal drug overdoses, first in acute hepatitis B, and second in hepatitis C infections, which are escalating to HIV from needle sharing (Pollini, 2019, p. 354). Although needle exchange programs are sometimes implemented, in the case of the Charleston, WV program, issues of litter, harm and community anxiety shut them down, furthering the extent of the problem (Sipe, 2019). And with opioids being sent by the millions to many parts of the country, but especially West Virginia, it has become extremely difficult to get ahead of the deadly problem.

With the opioid epidemic rapidly becoming more deadly in West Virginia, the DEA announced the substances causing the most overdose-related deaths in 2015 were controlled prescription drugs (CPDs), heroin, fentanyl, and methamphetamine. However, psychoactive substances (NPSs), marijuana, crack, and cocaine were also being spread throughout the state (2017). Opioid abuse is the long-leading drug problem, but in the past five years, heroin and fentanyl have become a more grim and pressing issue (DEA, 2017; Sisk, 2019). Pharmaceutical fentanyl is an approved drug to treat severe pain, often due to advanced cancer pain; it is between 50-100 times more potent than morphine. Illegally produced fentanyl, on the other hand, is less expensive to make but is much more dangerous, as it has, in some cases, been found laced with heroin or cocaine without the users' knowledge (Sisk, 2019; CDC, 2018). 
The situation has become so dire, medical professionals are overwhelmed, and it has taken a toll on funeral directors who have found themselves overwhelmed with bodies of often young victims who have overdosed (Eyre, 2017). Eyre (2016) stated, "In six years, drug wholesalers showered the state with 780 million hydrocodone and oxycodone pills, while 1,728 West Virginians fatally overdosed on those two painkillers" (n.p.). That is enough for roughly 1.792 million people in the state to have 433 pain pills each (Eyre, 2016; U.S. Census Bureau, 2019). However, even with the general public and public officials finding themselves traumatized by the epidemic, the country nor the state have made universal efforts to find long-lasting solutions. Stellin (2018) argues that this problem throughout Appalachia is much to do with the way people who are addicted are stigmatized. The language that is used about the opioid epidemic has become so common, and it does nothing but stigmatizes and others those using, their families and the region (Stellin, 2018).

Pollini (2019) cited Eyre (2017), where one professional said switching one medication for an opioid does not help those who are addicted, even if it is designed to help them get off of the more dangerous opioids. She later discusses that it is because of this thinking that the country is not finding solutions to the opioid crisis, especially in West Virginia. Though Szalavitz and Rigg (2017) argue that the current opioid crisis has not been linked to an increase in property crime, homicide, or other violent crimes like that of the 1970s heroin wave or the 1980s crack crisis, some West Virginian officials are othing those addicted by turning on them -- such as in the instance Pollini (2019) is discussing of Charleston shaming "junkies," blaming them for a "crime wave" throughout the city, and choosing to discourage programs that help those addicted to opioids so much so that the programs have since closed down (p. 355). It is possible that these harsh assumptions and prejudices are hindering efforts toward a solution to the opioid crisis; and instead, othering is taking its place.

Standpoint Theory

Harding and Wood (2014) argue that the most efficient way to discover the way the world works is to ask for the perspectives and standpoints of groups in the margins of society. Orbe (1998) furthers this idea by stating, "Theorizing from a marginalized perspective simultaneously unites and differentiates 
experiences without essentializing them" (p. 1). Standpoint theory, the theory that an individual's perspective is shaped by their personal, political, cultural, and religious experiences, focuses on acknowledging that perspective to emphasize how that person interacts with themselves and the world (Harding and Wood, 2014; Orbe, 1998; Sosulski, 2009). Beginning to find answers to a marginalized group's individual experience has the potential to be more accurate when going straight to the source--the marginalized group. Bell (2008) furthers the argument, suggesting that in order to tell the stories of an insider in West Virginia, some action must be taken to give the participants the chance to tell their story, rather than having a journalist come in, tell a story, and then leave. Bell (2008) further discusses West Virginia, saying, "The replication of power and powerlessness in this region has meant that many in the population have been taught that rising up against the power-elite engenders little progress...thus, many in Central Appalachia have remained silent about the injustices they face" (p. 47). However, if they were able to tell their stories in a way that highlights the solutions led by individuals in West Virginia, perhaps that would change.

Further, Standpoint theory's objective is to emphasize and allow those who are not from the dominant voice to tell their perspective of their own experiences, the social structure, and relationships with power (Orbe, 1998; Sosulski, 1998; Harding and Wood, 2014). In this circumstance, those a part of the dominant culture are not the insiders--rather, it would be the minor. However, identity with these insiders can be extremely complicated. Sosulski (2009) argues the marginalized groups are forced to develop multiple identities about their circumstances because, to survive, they have to understand both themselves and their world from their perspective, as well as themselves and the world in terms of the dominant power. Yet it is still necessary for them to tell the story because they know their experience better than an outsider. Sosulski (2009) further states, "These insider perspectives are the fruit of experiences of hardship and oppression, offered by people who are reflective about those experiences. These insights provide multifaceted standpoints that are inaccessible to people in dominant social groups who may be invested in maintaining the status quo" (p. 227). 
When discussing J.D. Vance's (2016) Hillbilly Elegy on the other hand, the insider/outsider argument becomes much more complicated. Vance (2016) describes his life as the insider--he grew up in Appalachia and discusses the loss of jobs, poverty, and the low quality of life he lived while growing up. Vance (2016) shows an extremely specific aspect of Appalachia, and because he is considered an insider, his perspective spread into what many believe more now than ever as what Appalachia is and represents. Although his story might match many who are living in the area, it shows such a story that Elizabeth Catte (2018) argues is made only to show an exploitative and invasive version of Appalachia to observers. However, Catte (2018) is also an insider to Appalachia. In her book, What You Don't Know about Appalachia, she discusses the ways she had to come to the defense of Appalachia, especially after Hillbilly Elegy came out. Catte (2018) argues further that it is because of stories like Vance's (2016) that Appalachia is considered as an "other America" ( p. 9). Othering has played into insider/outsider perspectives throughout the region because Appalachia does not have the dominant narrative. If the people who are telling the stories are not an insider, often the stereotypes and othering are further developed. In an interview with NPR, Catte (2018) discusses that having accurate coverage on Appalachia is what the area needs. Rather than focusing merely on the negative aspects that Vance (2016) emphasizes, insiders should have the chance to tell more stories than one that tells of poverty-stricken people who are arguably responsible for their situation. And although deciding who gets to tell the story becomes much more complicated when taking into account Vance's (2016) and Catte's (2018) depictions of Appalachia, the goal of the documentary is to show an accurate depiction of the perspectives of the participants, contributing to getting more coverage about Appalachia in a respectful and non-exploitative way.

Further, Standpoint theory is especially relevant to the proposed study, as it offers the chance for those who consider themselves insiders, either by birth or by choice, to tell their perspective truths regarding the opioid epidemic and othering in West Virginia. Although the argument for what makes an insider or an outsider is extremely complicated, the people telling their individual stories, who also consider themselves an insider to their respective situation, have a valuable story to tell (J. Wright, 
personal communication, Jan. 10, 2020). As all standpoints are respective "truths," (Orbe, 1998, p. 2), it is important to show those perspectives that are not being told in the dominant narrative in this case. The stories in the margins of the dominant accounts should not be told by those not living it. As Orbe (1998) explains “research must begin from a person's concrete lived experiences and must include the experiences of marginalized group members within the process of inquiry in meaningful ways" (p. 5), the perspectives that will be shared in the project will be those in the margins. The project will aim to emphasize that the experts have the authority and autonomy to be a part of the project in a meaningful way, and that their perspectives provide a valuable counterpoint to the dominant narrative.

With all of this in mind, the basis of the documentary will be through Standpoint theory - the theory that the insider is the one who truly understands their experience (Orbe, 1998). The way this will be conducted is by interviewing subjects who consider themselves insiders. Although it can be difficult to distinguish who is who in regard to insider/outsider standpoints, the purpose of the documentary is to show that, because they are directly and secondarily affected by West Virginia's opioid epidemic, they have authority to tell others about it. While the film will be looking at othering as well, the underlying theoretical perspective will be that of Standpoint theory. As Orbe (1998) states, "Although these cocultures exist all around us, their experiences are often made invisible by the pervasiveness of the dominant culture" (p. 2), which is why it is important they are able to tell their story.

\section{Methodology}

Growing up seeing those with substance use disorders in my family in rural Utah, I realize that I have some perspectives that would give me insider access when researching the opioid epidemic. I not only saw the stereotypes and the othering that occurred first-hand, but I was also stereotyped, as everybody knows each other in the small town. Whether there was a robbery, somebody overdosed, or even if it were just rumors, I was often labeled as "one of them." I recognized at a very young age that although there is a lot of hurt in the case of addiction, both for the person with the disorder and those around them, the stereotypes were doing nothing to solve the problem at hand. I knew that I wanted to be able to tell the stories of those affected, as I recognized each person involved as individuals rather than 
just "junkies" or "enablers." However, as I have been in West Virginia for only a short time, I am very much an outsider in that regard.

The opioid epidemic in West Virginia is similar to Utah's, but stereotypes are very different in Appalachia than in the U.S. West. Consequently, I am hoping that explaining to each participant my story, the ways that I can empathize and understand their situation as an insider, and the ways that I am an outsider wanting to tell their story from their perspective, will give them an opportunity to recognize me as somebody that truly cares about the work they are doing and the story they are telling. And realizing that to be an insider or outsider can be from an abundance of perspectives and realities, I have had them tell me where they believe they stand as I did them in order to refrain from being inflexible and a contributor to the stereotypes and othering they already face.

In order to complete the project in this way, the documentary film is roughly 17 minutes long, following three main experts, through their work and/or home life. It is proposed that the film will be completed by March of 2020 .

The goal of the documentary is to answer the following research questions:

RQ1: To what extent does including the perspectives of documentary subjects throughout the production process lead to a fuller story from the perspective of those subjects?

RQ2: In as massive of a situation as West Virginia's opioid epidemic, what information do those on the frontlines suggest is the most important for others to know?

The three experts consider themselves insiders of the epidemic, which is why I have chosen to rely on them so heavily. All three stories and expertise are especially crucial because they are the ones seeing it every day. By having a documentary film that gives them the chance to discuss their own stories and perspectives, the story will have a higher standard than if I were to come in, "tell their story for them with my limited expertise and then leave without any follow-up, feedback or acknowledgment" (J. Wright, personal communication, Jan. 10, 2020). Upon gathering the signed consent form to be filmed, the interviews will be semi-structured, giving them a chance to tell their story without being too confined by questions given. 


\section{Participants}

The following three participants have been included in filming the documentary: Caity Coyne, Chad Akers and Michelle Akers. The three consider themselves insiders to the West Virginia opioid epidemic, as they have put themselves on the frontlines and see the effects of it as it happens. Caity Coyne

Caity Coyne, a journalist at the Charleston Gazette Mail will be interviewed on her work that she has done regarding the epidemic; Coyne has been around the state discussing needle exchange programs, the millions of opioids shipped to rural West Virginia and much more. Coyne considers herself as a traditional outsider, as she is from California, but she has earned insider status by gaining a nuanced understanding of the issues that even some people who have been in the region for years do not have. She forces herself to be an insider in order to tell the stories that the dominant narrative is not giving. Wright argues that to be willing to completely immerse oneself into the places they are located gives them the privilege of taking place as an insider, as they are living the experiences without assistance or a second perspective (J. Wright, personal communication, Jan. 10, 2020).

Chad and Michelle Akers

Next, Chad Akers, a funeral director in Logan County will be interviewed with clinical psychologist Michelle Akers, his wife, who works with those struggling with addiction at the Day Report Center. Chad and Michelle are Native West Virginians who have dedicated their full attention on the opioid epidemic. They volunteer with people who have substance abuse disorders, while also running the Day Report garden and helping with the Logan Food Pantry. Both consider themselves as insiders by birth and by choice, and because of this their expertise is especially relevant, as they are on the frontlines of West Virginia's opioid epidemic. Both will be filmed both about their personal experiences in the epidemic, as well as the effects of the epidemic in their work and volunteering experience.

Storyboard 
It is intended that the documentary will follow the stories of each participant in the work they are doing to either discuss the opioid epidemic or to get those with substance abuse disorders clean. There are eight scenes of the documentary, following as such.

\section{Scene 1: Caity Coyne}

The story will begin with b-roll footage and then go into Caity Coyne discussing the region, the problem and then introduce the Akers by telling the story of how she met Michelle.

Scene 2: Michelle introduces herself and discusses the work she does at the Day Report Center, as well as how it has changed with the rise of the opioid epidemic.

\section{Scene 3: Chad Akers}

After transitions to the funeral home, Chad Akers is introduced. He describes the work that he does as head of the funeral home and about an award he was granted the Dodd Award from the Funeral Association.

\section{Scene 4: Fresh Start Garden}

It is here in the film that the volunteer work the Akers do is shown. Chad will be going to the Fresh Start Garden, where he will grab eggs from their chickens there and introduce the positive impacts that are continuing to bring the Logan community together.

Scene 5: Chad and Michelle - Bruising the monster

The film will then focus on Chad and Michelle at home. They will be transitioning the conversation to making a difference. They will discuss wanting to bruise the theoretical monster through doing small things to help; the goal of the scene is to show that although there is a major drug problem in West Virginia and in the U.S., any kind of help can lead to differences in either an individual's life, or in the epidemic itself.

Scene 6: Chad on community

In this scene, we will return to the funeral home, where Chad talks about Logan, and how much of the town has reacted to the epidemic. He will be stressing the idea that although many see Logan as "the friendliest town in West Virginia," the community has not bonded together to stop the epidemic from 
getting worse. He will be discussing his fear that nothing will change for the better, as well as that the loss of the population and businesses will drive everyone out of the town.

\section{Scene 7: Caity on Solutions}

Here, the film starts to wind down. Caity will be talking on the need for people to come together and be loud about the work they are doing to fight the epidemic. She will be talking about the ways that stereotypes affect characters of people who hold them.

Scene 8: Chad and Michelle on treatment

To conclude the film, Chad and Michelle will have a conversation about the things people need to know about the epidemic. They will be discussing that treatment works, people recover and giving chances to people who have substance use disorders can change the conversation. Credits will then roll.

All three experts will be filmed through the months of January-March to capture their stories as insiders in the opioid epidemic and their experiences with othering and stereotypes regarding it.

Further, the film has been sent to the Akers and Caity asking them three main questions (See Appendix C). There will be a virtual follow-up with them to see how they felt about the film and their portrayals.

The documentary will be submitted to 100 Days in Appalachia and will be posted to YouTube and my personal website. Because of COVID-19, I may not be able to show it in Logan in May as previously planned, but it will be postponed to a later date.

\section{Discussion}

The documentary film is meant to contribute to the conversation on the harmful othering by insiders and outsiders of West Virginians experiencing the opioid epidemic, while also showing how complex the situation in West Virginia is. I am hopeful that there will be discussion around making helping individuals directly affected by the epidemic throughout Appalachia. Further, the documentary aims to make viewers consider what information is needed to better understand the opioid epidemic. The interviews in the film were selected to highlight the voices of those trying to help the cause, because they are helping individuals with substance abuse disorders and are in the fight to destigmatize those 
individuals. Many stories and depictions of West Virginia and Appalachia are controversial and stereotypical (Angelos, 2019; Hess, et al., 2018; Huettner, 2011), such as in the case of Shelby Lee Adams, who has been accused of making "poverty porn" (Huettner, 2011). His work is often critiqued as stereotyping Appalachians as being nothing more than "hillbillies" (Scott, 2009; Rubin and York, 2019; Stewart, 1996), a harmful narrative that has been pushed on Appalachians for decades. My documentary film hopefully contributes to breaking that narrative by giving the participants the chance to tell their story with as little restriction on their voice as possible.

To answer RQ1 and RQ2, I filmed and produced a 17 minute documentary film. RQ1 asked to what extent keeping participants involved through the documentary process leads to a fuller story. I answered RQ1 through the filming process. I kept the Akers and Caity informed on all major changes, and I had the participants choose where the interview would take place, as well as allowing them to talk about topics most important to them by framing the interview questions more as talking points. I went to Logan intending to strictly adhere to the interview protocol, but once I realized there was more for my participants to say, the interview turned more into a back-and-forth conversation. I wanted the participants to help create the documentary from their perspective. The story was fuller than if I had given direction without their input and edited to show the story I wanted to tell. Through allowing each participant to share her/his story I was able to answer RQ1.

RQ2 asks what those on the frontlines of the West Virginia opioid epidemic find most important for viewers to know about the epidemic. Throughout the entire filming process, I would ask what they thought was most important to tell and for people to know. One scene, which I didn't end up including for length and context to the rest of the documentary, was specifically on the way that the Akers and Caity thought West Virginia was targeted. They discussed the amount of prescription pills sent to the state in a very short amount of time; although I couldn't include those interviews in the documentary, slides with those statistics were instead included in the film. This was to remind viewers that the state is the hardest hit, and the people on the frontlines are still struggling to make a dent. The Akers especially thought it relevant to have the statistics throughout the documentary, while they are still telling their perspectives on 
the epidemic. RQ2 is also addressed in the last scene, where the Akers and Caity have a conversation of what they believe people should know about the epidemic. All three discuss how treatment works, people do recover and the communities need to come together to encourage policy that will be specifically to help fight the West Virginia opioid epidemic. However, further addressing what other individuals' perspectives are about the epidemic aside from the three participants could also be beneficial in continuing to address RQ2, creating a fuller story.

Standpoint theory informed the storytelling process throughout the production of this film. Throughout the film the participants, who saw themselves as insiders, were able to tell the story from the frontlines. Allowing them to tell their story can be difficult, and perhaps I gave them too much leeway on telling the story rather than showing it. Showing the Akers and Caity interacting with their communities would further Catte's (2018) call to action to have accurate coverage of Appalachia, as it would emphasize a bigger picture of the community than what only interviews could do. I wanted to show them as experts as much as possible, but not having the footage of them at work detracted from my attempt to establish their insider and expert status. With each step I took, I worked to have the self-identified insiders tell the story, I talked with them extensively about the fluidity of their perspectives and went into editing with as much framing with the theory as possible, by emphasizing the importance of insider status through the scenes I chose to show. As Harding and Wood (2014) argue, the most efficient way to discover the way the world works is to ask for the perspectives and standpoints of groups in the margins of society, and that was my primary goal from the beginning of the project.

Standpoint theory can be beneficial when telling stories, but it can be difficult to implement when creating a documentary film. Harding and Wood's (2014) argument that asking for the perspectives and standpoints of groups in the margins of society to discover how the world works is still critical. The perspectives of individuals who are underrepresented should be heard through their own voices. However, when creating a film, it is still important to hold structured interview questions to tell their story in a more effective way. In my project, I wanted to allow the participants to tell me what they thought was most important for people to know to answer RQ2, but by giving too much freedom, it can be easy to stray 
from the story. That being said, I will still aim to include Standpoint theory in my future work, agreeing with Sosulski (2009), who argued that individuals inside perspectives "provide multifaceted standpoints that are inaccessible to people in dominant social groups who may be invested in maintaining the status quo" (p. 227).

Further, insider/outsider perspectives have impacted both my work and personal identity. There are many roles that I play depending on any given circumstance. While researching insider/outsider perspectives, especially in regard to Sosulski's (2009) argument that marginalized groups are forced to consider multiple identities, I started learning to consider perspectives of all involved when I approach and interact with others. For example, this research has assisted me in recognizing I could be seen as an outsider to their experience, however, empathy for their situation can create understanding that mirrors a form of insider status, even in small ways. My understanding aligns with the insights from Sosulski (2009) who articulates the complexity of insider/outsider identities. Moreover, I have started to wonder if it is possible to truly be an insider or an outsider. While interviewing the Akers for the first time, I went with them to a meeting, where they discussed people with substance abuse disorders who they were trying to get into rehabilitation. Going into the conversation, I expected to understand and relate based on my own experience. I felt that I had some insider status because of what I experienced with my family. Regardless of that experience, I quickly realized I was not an insider just because I had done research and had seen the epidemic's effects in my life. I could relate to the stress in the room, but the depths of information around just a few people's addiction was something I struggled to could not comprehend. It was then that I began realizing it is impossible to attempt to justify why one is an insider/outsider thoroughly, but continuing the conversation is critical nonetheless.

Some limitations included not being able to film the Akers with the community, which the Akers agreed would have been great to have included had there been more security and time. Much of this was due to the HIPAA regulations that prevented work done with others aside from Michelle, Chad and I in the office. Much of the footage that was shot in the office, which included showing people in photos and in person, was not able to be shown because of those regulations. Further, there was footage which 
involved a police officer, EMS worker and a social worker that also could not be used, as they were saying names and giving addresses of those they were trying to get into rehabilitation. There was footage shot over the course of an afternoon that included going on the Quick Response Team's drive. One camera was with the police officer, EMS worker and social worker, while I had the other with Chad and Michelle. Although no locations were explicitly given, names were, causing the Akers' concern, so it was not put in the film. The COVID-19 pandemic in Spring 2020 also caused filming scheduled in March to be canceled, which would have included the Akers interacting more with the community, as well as footage with a few of the people they helped through rehabilitation. Finally, using the interview questions as talking points, rather than posing the questions directly was also a limitation, as it left gaps in the stories and perspectives. Had they been asked as direct questions, direction to answer the research questions would have been provided. Going forward, it would be beneficial to continue building on the relationships I have, especially in giving more context to what the Akers do, what their community thinks about their work and potentially more information on those who do not agree with their efforts. Participant Feedback

Through email and Zoom, participants provided feedback after immediately watching the documentary to satisfy the fulfillment of member checking. All were asked the three initial questions (See Appendix C). The Akers' responses to the film were that it fulfilled the requirement of number one and two, that it was accurate, respectful and reasonable. For example, Michelle mentioned, "We both felt that you found a way to make Logan look like a clean little coal town. I was very relieved that your documentary wasn't the typical "poor ole southern [West Virginia]" stereotype. You stayed away from that, and I appreciate that very much" (M. Akers, personal communication, April 15, 2020). They said they did not feel there were changes that needed to be made and asked instead if more films similar to this one could be implemented to create a small series, or if the project could be made longer following its submission to West Virginia University (C. and M. Akers, personal communication, April 15, 2020). Some ideas for further documentaries that the Akers and I discussed included getting more usable footage for the QRT, showing community interactions, provide a fuller picture of Logan as a whole and getting 
the opinions of those who disagree with the work being done in the town to fight the epidemic. Chad and Michelle did mention they would have liked to see scenes in the documentary that had to be taken out, including the QRT ride along and a scene with Chris Newsome, a man who graduated from the Day Report Program five years ago.

When asked how the Day Report Center has changed with COVID-19, Michelle sent me an email about the adjustments that had to be made to keep staff and clients safe (See Appendix D). The Center is still open, but with only limited staff; they are working through Telehealth. However, with much of the region left without access to $\mathrm{WiFi}$, those services cannot reach as far as they do in person, so there have been many relapses (M. Akers, personal communication, April 29, 2020). The Center's staff do continue to call clients every day to check in, and they continue to help overdose survivors get into detox beds and inpatient care. The Fresh Start garden has been run by Chad, their sons, and a case manager at the Day Report and his father while the pandemic lasts, giving the chicken eggs to the food pantry and the Williamson Farmer's Market to help with those struggling.

At the end of the film, there is an epilogue scene, where Chad, Michelle and I did a Zoom meeting to discuss the film and add stories and context to their work. Because COVID-19 kept me from filming more with the Akers, the meaning of the epilogue is to add to the film and to fill that void. It also gave background for me and the viewers by hearing stories that built their perspective around the drug epidemic. We specifically discussed the stigma around helping individuals with substance abuse disorder to give context to othering, and Michelle gave context to other individuals' perspectives as "not wanting anything to do with "those individuals"” (M. Akers, personal communication, March 13, 2020).

However, the Akers shared positive stories about overcoming the fear of being stigmatized to emphasize that there can be change, as well. Through getting people involved with the cause, they stated there were people that started sharing their own stories once they saw that they had a voice. We talked about expanding the project to tell those perspectives because, as Chad said, "There is so much more to this story that you can't get into 15-20 minutes" (C. Akers, personal communication, March 13, 2020). 
Finally, the Akers finished by telling how their work has changed due to COVID-19, and Michelle talked about the work that her team was doing to ensure that those in recovery are staying clean and are continuing their group therapy. I thought it was important to include in the film to show how they are working in the face of the pandemic to still make a change in the community, even if they have limited resources. I think it pulls everything together to have the epilogue because it gives a fuller perspective of people who are on the frontlines, and it helps add context and understanding to their work. Future Research

Future researchers should use the information found in the documentary to continue the conversation about the epidemic, insider/outsider statuses, stereotyping and othering. Answering my RQs has given credence regarding othering and Standpoint theory. Having those who are notoriously othered answer questions around what it is like to be in the minority regarding the epidemic--further, interviewing those who are othered provides evidence of what Orbe (1998) argues: "Theorizing from a marginalized perspective simultaneously unites and differentiates experiences without essentializing them" (p. 1). Emphasizing that the participants were the subject experts who should tell the story links the two topics together more firmly than if I had told a story as someone who told a story without their input.

As suggested by the Akers, continuing to expand this project would be a beneficial start. By viewing the work that was conducted in this project, one would have foundational information to continue the research on examining othering and the epidemic through the lens of Standpoint theory. One option would be to involve individuals that are a part of the cause, as well as those who are not, as it would flesh out the story of Southern West Virginia's epidemic that I have started through this project, and could potentially lead to an understanding of the harmfulness of othering. The research could extend to other parts of the state or remain in Logan around the Day Report Center. Giving more of a quantitative groundwork around the topic would also be beneficial in continuing the research. For example, one could look at the effectiveness of centers like the Day Report Center to confirm Michelle's point that treatment does work and that having stigma surrounding a disorder does nothing but further the harm done by the epidemic. 


\section{Conclusion}

West Virginia's opioid epidemic is vast and daunting. Coupled with othering and insider/outsider identity experiences and understanding, the epidemic can seem unmanageable, as the othering has brought harsh stereotypes that prevent the state from getting the unified help they need. However, individuals throughout the state are fighting for the lives of individuals affected directly and secondarily, and it is important that their voices are heard from their perspective. This project's aim was to allow them to do so, and it is hoped the conversation that was started in the film will continue, assisting in discouraging stigmatization and othering that has been created within the opioid epidemic. From this we can learn about West Virginians perspectives and identities, which will contribute to our collective understanding of the effects of the epidemic on those on the frontlines. 


\section{Appendix A, Video Release Form}

\section{VIDEO RELEASE FORM}

I, the undersigned, hereby grant permission to the producer, Emily Morwood, the right to use my full name, biography, video image, likeness, and audio collected during this production.

I attest that I have voluntarily agreed to be filmed, and understand that my image may be edited, copied, exhibited, published or distributed and waive the right to inspect or approve the finished product wherein my likeness appears. Additionally, I waive any right to royalties or other compensation arising or related to the use of my image or recording. I also understand that this material may be used in diverse settings within an unrestricted geographic area.

Photographic, audio or video recordings may be used for ANY USE which may include but is not limited to:

- Presentations;

- Courses;

- Online/Internet Videos;

- Media;

- News (Press);

By signing this release, I understand this permission signifies that photographic or video recordings of me may be electronically displayed via the Internet or in the public setting. There is no time limit on the validity of this release nor is there any geographic limitation on where these materials may be distributed.

I, the undersigned, shall not be given any fees for the services provided for this production. By signing this release, I acknowledge that I have completely read and fully understand the above release and agree to be bound thereby. I hereby release any and all claims against any person or organization utilizing this material.

Signature: Date

Address:

Telephone:

Email :

If this release is obtained from a person under the age of 18, then the signature of that person's parent or legal guardian is also required.

Parent's Signature Date 


\section{Appendix B, Interview Protocol}

1. Tell me about yourself.

a. Demographics

i. Name, age, location

b. Are you from WV?

c. What's something you think people might not know about WV?

d. How has the epidemic impacted you personally?

2. Tell me about your work.

a. Describe your work related to the opioid epidemic.

b. Tell me a success story you have seen in your work/volunteer work.

c. Would you share a story with me that illustrates a challenge you have experienced in your work?

3. Through the years, how if at all, has your work changed?

4. What kind of stigmas/stereotypes have you run into with other people about the epidemic?

5. Have there been stigmas/stereotypes that you have had to overcome when writing about the epidemic?

a. How do you think stereotypes and stigmas affect people's responses to the epidemic?

b. Would you share a story with me?

6. How do you feel stereotypes and stigmas affect people's responses to the epidemic?

7. Do you know how stereotyping has affected people you know who have substance abuse disorders?

a. Specific examples

8. How, if at all, do you feel that you understand the opioid epidemic in West Virginia?

9. How, if at all, have opioids influenced your life?

a. Would you share a story with me?

b. Can you share some specific examples of the effects of opioids that people might not be aware of?

10. How do you feel the media has affected the epidemic, inside and outside of WV, especially people's views of it?

11. Do you feel that people outside of West Virginia understand the epidemic?

a. Specific examples

12. What would you like people to know about the epidemic?

a. What would like them to know about West Virginia?

b. What would you like them to know about addiction and substance abuse disorders?

c. Specific examples. 


\section{Appendix C, Final Questions}

1. Is the information in the film about you, your job, and your personal life accurate?

2. Do you feel that the way you are portrayed in the film reasonable and respectful?

3. Do you think there are any areas that need to be explained more clearly? 


\section{Appendix D, Michelle Akers' Email}

"COVID-19 has changed much of what we do. The Day Report Center is functioning with limited staff daily and all services are being conducted through telehealth. However, in our region, many people do not have the resources or access to Wi-Fi, so delivery of services has been difficult. We have seen a lot of relapses, so I have been busy. Chad has continued his work at the garden with our staff. The clients have not been permitted to come out to work due to the restrictions, so the garden has been a challenge. Chad and our sons and Tyler (case manager) and his father have been prepping the raised beds, planting and taking care of the plants in the greenhouse and caring for the chickens. We have still been giving eggs to the food pantry and to the Williamson Farmer's Market to help those in need. Chad unfortunately has also been affected with his work as funerals are limited to 10 people and one of the COVID-19 deaths came to his funeral home.

The staff at the Day Report Center has continued to call clients every day to check in on them. Some are getting sick of our daily calls. We have assisted with overdose survivors in getting them into detox beds and inpatient care. We have had some problems with linkage to inpatient facilities due to a number of barriers (transportation, access, availability). Many of our daily treatment clients have relapsed unfortunately. To try to help those clients, we have had them telephone or telehealth with a recovery coach several times a week and we have increased individual therapy to two times a week. We are trying to reach out every day. Sometimes it has helped, others have stopped taking our calls. We are also helping clients who have limited food by getting them food baskets from the pantry and meeting them in a public place or at the Day Report Center to deliver the food." 


\section{References}

Angelos, A. (2019, Oct. 23) "I began to question the honesty of it": Stacy Kranitz on the flaws of documentary photography. It's Nice That. Retrieved from https://www.itsnicethat.com/features/stacy-kranitz-as-it-was-given-to-me-photography$\underline{231019}$

Bell, S. (2008). Photovoice as a Strategy for Community Organizing in the Central Appalachian Coalfields. Journal of Appalachian Studies, 14(1/2), 34-48. Retrieved January 9, 2020, from www.jstor.org/stable/41446801

Canales MK. (2000). Othering: toward an understanding of difference. Advances in Nursing Science, 22(4), 16-31. Retrieved from http://search.ebscohost.com.www.libproxy.wvu.edu/login.aspx?direct=true \&db=c8h\&AN=10711 $\underline{9953}$

Catte, E. (2018, Jan. 31). Historian Makes Case for 'What You're Getting Wrong in Appalachia' in New Book (K. McEvers). Retrieved from https://www.npr.org/2018/01/31/582240482/historian-makes-case-for-what-you-are-gettingwrong-about-appalachia-in-new-book

Catte, E. (2018). What you are getting wrong about Appalachia. United States: Belt Publishing. CDC (2018). Opioids Portal. Retrieved from https://www.cdc.gov/opioids/

Cenziper, D., Corio, E., Hooper, K., \& Soule, D. (Oct. 18, 2019). The Opioid Files: 'They looked at us like an easy target.' The Washington Post. Retrieved from https://www.washingtonpost.com/graphics/2019/investigations/west-virginia-opioid-legal-battlefoster-care/ Conquergood, D. (2003). Performing as a Moral Act: Ethical Dimensions of the Ethnography of Performance. Literature in Performance. Retrieved from http://www.csun.edu/ vcspc00g/603/PerfasaMoralAct.pdf. 
Del Vicario, M., Bessi, A., Zollo, F., Petroni, F., Scala, A., Caldarelli, G., . . Quattrociocchi, W. (2016). The spreading of misinformation online. Proceedings of the National Academy of Sciences of the United States of America, 113(3), 554-559. Retrieved from https://www.jstor.org/stable/26467425

Eyre, E. (2016, Dec. 17). Drug firms poured 780M painkillers into WV amid rise of overdoses. Charleston Gazette-Mail. Retrieved from https://www.wvgazettemail.com/news/cops_and_courts/drug-firms-poured-m-painkillers-intowv-amid-rise-of/article_99026dad-8ed5-5075-90fa-adb906a36214.html Eyre, E. (2017, May 9). Trump officials seek opioid solutions in WV. Charleston Gazette-Mail. Retrieved from https://www.wvgazettemail.com/news/health/trump-officials-seek-opioidsolutions-in-wv/article 52c417d8-16a5-59d5-8928-13ab073bc02b.html Eyre, E. (2017, Sept. 27). Opioid crisis drives a grim business in WV: body transport. Charleston Gazette-Mail. Retrieved from https:/www.wvgazettemail.com/news/health/opioid-crisis-drivesa-grim-business-in-wv-body-transport/article cf303489-aa79-5bd5-89f8-fee0840c262d.html Eyre, E. (2018, Dec. 19). Drug firm poured 3M opioids into WV town in just 10 months, report says. Charleston Gazette-Mail. Retrieved from https://www.wvgazettemail.com/news/health/drug-firm-poured-m-opioids-into-wv-town-injust/article d229b33b-c55a-5451-ab3f-b545476516d4.html Fallis, D. (2014). A functional analysis of disinformation. In iConference 2014 Proceedings (p. 621 - 627). doi:10.9776/14278 Griffith, A. (1998). Insider / Outsider: Epistemological Privilege and Mothering Work. Human Studies, 21(4), 361-376. Retrieved from http://www.jstor.org.www.libproxy.wvu.edu/stable/20011213 Gualda, E., \& Rúas, J. (2019). Conspiracy theories, credibility and trust in information. Communication \& Society, 32(1), 170-194. https://doiorg.www.libproxy.wvu.edu/10.15581/003.32.1.179-195 
Harding, S., \& Wood, J. T. (2009). Standpoint Theory. In E. Griffin (Ed.), A first look at communication theory (pp. 447-453). McGraw-Hill Higher Education.

Harvey, D. (2003). The True Meaning of Pictures: Shelby Lee Adams' Appalachia. Variety Movie Reviews, 18. Retrieved from http://search.ebscohost.com.www.libproxy.wvu.edu/login.aspx?direct=true \&db=f3h\&AN=27064 $\underline{706}$

Hess, M. E., Casapulla, S. L., Brust, P., Cickovskis, K., Lang, J., Macys, K., \& Slusher, E. (2018). Localized Othering: Understanding Regionally and Geographically Bound Stereotypes in Appalachia. Journal of Appalachian Studies, 24(1), 8-25. https://doiorg.www.libproxy.wvu.edu/10.5406/jappastud.24.1.0008 Huettner, J. (2011). Capitalist realism or poverty porn? Retrieved from https://hyperallergic.com/28555/capitalist-realism-or-poverty-porn/ Light, M. (2006). Coal Hollow: Photographs and Oral Histories. California: University of California Press.

Lopez, L. (2017, Sept. 6). There's only one deadly conspiracy Americans really need to think about. Business Insider. Retrieved from https://www.businessinsider.com/opioid-crisisconspiracy-2017-9

Moyer, M. W. (2019). Why We Believe Conspiracy Theories. Scientific American, 320(3), 5863. Retrieved from http://search.ebscohost.com.www.libproxy.wvu.edu/login.aspx?direct=true $\& d b=b u h \& A N=13468$ $\underline{3258}$

NIDA (2019). West Virginia Opioid Summary. Retrieved from https://www.drugabuse.gov/opioid-summaries-by-state/west-virginia-opioid-summary Orbe, M. P. (1998). From the standpoint(s) of traditionally muted groups: Explicating a cocultural communication theoretical model. Communication Theory. https://doi.org/10.1111/j.1468-2885.1998.tb00209.x 
Phillips, C., \& Earle, R. (2010). Reading difference differently?: Identity, epistemology and prison ethnography. The British Journal of Criminology,50(2), 360-378. Retrieved from http://www.jstor.org.www.libproxy.wvu.edu/stable/43610763

Pollini, R. A. (2019). Wild... But Not So Wonderful—Responding to Injection Drug Use in West Virginia. American Journal of Public Health, 109(3), 354-355. https://doi-

org.www.libproxy.wvu.edu/10.2105/AJPH.2018.304937

Rubin, S. \& York, A. (2019, Feb. 21). Hillbilly. United States. The Orchard.

Scott, R. (2009). The Sociology of Coal Hollow: Safety, Othering, and Representations of Inequality. Journal of Appalachian Studies. https://www.jstor.org/stable/41446816

Sheldon, E. M. (2017, Sept. 13). HEROIN(E): An Interview With filmmaker Elaine McMillion Sheldon. Huffington Post. Retrieved from https://www.huffpost.com/entry/heroine-an-interviewwith-filmmaker-elaine-mcmillion_b_59b94b6ae4b0390a1564da33

Sipe, A. (2019, May 29). Health officials move focus off needle exchange, consider other options. WSAZ 3. Retrieved from https://www.wsaz.com/content/news/WSAZ-Investigates-NeedlesEverywhere-474520733.html

Sisk, T. (2019, April 30). Fentanyl-related Deaths Are the Highest in W.Va. This Is What They're Doing about It [blog post]. Retrieved from https://www.wvpublic.org/post/fentanyl-relateddeaths-are-highest-wva-what-they-re-doing-about-it\#stream/0 Sosulski, M. R. (2009). Developing a standpoint practice method with cases: Authority, subjectivity, reflection. Affilia: Journal of Women \& Social Work, 24(3), 226-243. https://doiorg.www.libproxy.wvu.edu/10.1177/0886109909337375

Stellin, S. (2018). Turning the Focus from Opioid Addiction to Treatment and Recovery. Nieman Reports, 72(1), 34-43. Retrieved from http://search.ebscohost.com/login.aspx?direct=true\&db=ufh\&AN=128189538 Stewart, K. (1996). A Space on the Side of the Road. Location: New Jersey: Princeton. 
Szalavitz, M., \& Rigg, K. K. (2017). The curious (Dis)connection between the opioid epidemic and crime. Substance Use \& Misuse, 52(14), 1927-1931. https://doiorg.www.libproxy.wvu.edu/10.1080/10826084.2017.1376685

U.S. Census Bureau (2019). West Virginia: Quick Facts. United States Census Bureau. Retrieved from https://www.census.gov/quickfacts/WV

Vance, J. D. (2016) Hillbilly Elegy: A memoir of a family and culture in crisis. Harper: Harper Press. Walsh, K. (2018). Review: Documentary 'Recovery Boys’ finds hope in addiction-ravaged West Virginia. LA Times. Retrieved from https://www.latimes.com/entertainment/movies/la-et-mncapsule-recovery-boys-review-20180628-story.html

Wood, M. J. (2016). Some Dare Call It Conspiracy: Labeling Something a Conspiracy Theory Does Not Reduce Belief in It. Political Psychology, 37(5), 695-705. https://doiorg.www.libproxy.wvu.edu/10.1111/pops.12285 